\title{
Variação fonético-fonológica do desvozeamento das plosivas e as atitudes linguísticas no hunsrückisch no Sul do Brasil
}

\author{
Claudia Camila Lara ${ }^{1}$ \\ Instituto de Letras e Artes, Universidade Federal do Rio Grande, São Lourenço do Sul, RS, Brasil
}

Resumo: O desvozeamento variável das plosivas bilabial, alveolar e velar do português brasileiro foi estudado a partir do contato com a língua de imigração alemã, hunsrückisch. Objetivou-se analisar a relação entre o processo variável e as atitudes linguísticas. O estudo orientou-se pela Sociolinguística Variacionista (LABOV, 2008 [1972]) e pelo estudo de atitudes linguísticas (KAUFMANN, 2011; VANDERMEEREN, 2005; LABOV, 2010). Constatou-se que a proporção de desvozeamento na análise de regra variável foi $2,6 \%$ e verificou-se no estudo de atitudes linguísticas que os núcleos familiares, geralmente compostos por avós, pais, irmãos, tios e tias, influenciam as práticas sociais, linguísticas e culturais na comunidade. Os resultados evidenciaram também que a escolaridade contribui para as atitudes, com práticas linguísticas em português brasileiro local no ambiente escolar, pois os falantes se orientam à cultura brasileira e à fala em português brasileiro local e buscam fugir ao estereótipo (LABOV, 2008 [1972]) do desvozeamento das plosivas.

Palavras-chave: Hunsrückisch; Variação Linguística; Atitudes Linguísticas.

Title: Phonetic-phonological variation of the devoicing of the plosives and linguistic attitudes in the Hunsrückisch in Southern Brazil

Abstract: The devoicing variable of bilabial, alveolar, and velar plosives in Brazilian Portuguese was studied from the contact with the German immigration language Hunsrückisch. The objective was to analyze the relationship between the variable process of bilabial, alveolar and velar Brazilian Portuguese plosives and Hunsrückisch and linguistic attitudes. The study was guided by Variationist Sociolinguistics (LABOV, 2008 [1972]) and by the study of linguistic attitudes (KAUFMANN, 2011; VANDERMEEREN, 2005; LABOV, 2010). The proportion of devoicing in the variable rule analysis was $2.6 \%$. As for the study of linguistic attitudes, and it was found that core family, usually composed of grandparents, parents, brothers, uncles, and aunts, influence social, linguistic, and cultural practices in the community. Finally, the results also showed that schooling contributes to attitudes, with linguistic practices of local Brazilian Portuguese in the school environment, as the speakers are oriented to Brazilian culture and to speak in local Brazilian Portuguese and seek to escape the stereotype of plosives devoicing.

Keywords: Hunsrückisch; Linguistic Variation; Linguistic Attitudes.

\footnotetext{
${ }^{1}$ Doutora em Letras pela Universidade Federal do Rio Grande do Sul. Professora do curso de Letras Português da Universidade Federal do Rio Grande-FURG, Campus São Lourenço do Sul. Orcid: https://orcid.org/00000002-7483-6789. E-mail: ccamilalara@gmail.com.
} 


\section{Introdução}

Dentre as variações linguísticas, objetivou-se investigar ${ }^{2}$ o fenômeno linguístico do desvozeamento das plosivas bilabial, alveolar e velar no português brasileiro falado em Glória, uma das comunidades da zona rural do município de Estrela, no Rio Grande do Sul, Brasil, e as atitudes linguísticas em relação ao desvozeamento das plosivas.

A variável "desvozeamento das plosivas" pode ser exemplificada em:

(1)

$\begin{array}{ll}\text { Variante 1: } & \text { Variante 2: } \\ \text { Manutenção de vozeamento } & \text { Aplicação de desvozeamento } \\ \text { abacaxi } & \text { apacaxi } \\ \text { dela } & \text { tela } \\ \text { Glória } & \text { Clória }\end{array}$

O traço linguístico em questão apresenta status social estereotipado. Para Labov (2008 [1972]), estereótipos têm como alvos comentários sociais estigmatizados. Assim, uma vez que o desvozeamento das plosivas é uma forma linguística desprestigiada, essa característica do hunsrückisch é reproduzida pela fala estereotipada dos imigrantes alemães em programas humorísticos de rádio, em livros e em propagandas e por membros de comunidades que não são bilíngues português-alemão, como também afirmam Altenhofen e Margotti (2011) e Gewehr-Borella e Altenhofen (2012).

O desvozeamento variável das plosivas / $\mathrm{b} \mathrm{d} \mathrm{g/} \mathrm{na} \mathrm{fala} \mathrm{em} \mathrm{português} \mathrm{brasileiro} \mathrm{local}$ (Pt) e hunsrückisch $(\mathrm{Hr})$ é um dos traços mais sensíveis à percepção dentre as marcas de contato linguístico e, para este estudo, analisou-se sob dois enfoques sociolinguísticos: por meio da análise de regra variável que captou o padrão de variação na comunidade, com a proporção total de aplicação da regra e com os grupos de fatores condicionadores do desvozeamento; e pelo estudo de atitudes linguísticas que verificou o status das variantes desvozeadas, da prática do Hr e do Pt na fala dos informantes.

A combinação dos dois procedimentos metodológicos pretendeu mensurar as atitudes linguísticas em relação ao $\mathrm{Pt}-\mathrm{Hr}$ e compreender o comportamento linguístico dos falantes e sua relação com os padrões variáveis locais. Para tanto, utilizaram-se dados de vinte e quatro entrevistas sociolinguísticas ${ }^{3}$, levantados por entrevistas sociolinguísticas, analisados por Lara (2013), de acordo com a linha laboviana (LABOV, 2008 [1972]). Para o estudo de atitudes linguísticas, com base em Kaufmann (2011), Vandermeeren (2005) e Labov (2010), a autora elaborou o questionário "As atitudes linguísticas no Português em

\footnotetext{
2 Neste artigo, delineou-se parte da investigação da Tese de Doutorado de Lara (2017) com o intuito de apresentar pontualmente a pesquisa realizada.

${ }^{3}$ Para a coleta de dados, seguiu-se os procedimentos éticos de informação aos participantes sobre os objetivos da pesquisa e de preservação de sua identidade, bem como se preencheu o termo de consentimento livre e esclarecido. A coleta de dados ocorreu em um período em que não havia a obrigatoriedade de submeter ao comitê de ética; os informantes foram contatados e as entrevistas realizadas em 2011 e 2012.
} 
contato com o Hunsrückisch" (LARA, 2017, p. 144-155), estruturado em seis blocos com perguntas para captar o perfil, comportamento e a realidade linguística dos informantes de Glória.

Os resultados dos estudos, de variação e atitudes linguísticas, evidenciaram que as marcas linguísticas dos falantes em relação ao Pt de contato com o Hr estão em declínio, de forma lenta, na comunidade de Glória, em uma perspectiva de mudança linguística em curso. Isso quer dizer que as práticas bilíngues perduram em momentos de interação social entre os informantes e demais membros da comunidade, com amigos, no trabalho e nas diversas relações sociais, também fora da comunidade.

Estruturou-se este artigo, primeiramente, com uma caracterização da comunidade de fala envolvida, Glória, no contexto da imigração alemã, e pela abordagem ao contato $\mathrm{Pt}-\mathrm{Hr}$ em termos linguísticos e sociais. Depois, revisaram-se estudos de variação e mudança linguística e de atitudes linguísticas. Em seguida, descreveram-se os métodos e procedimentos metodológicos e apresentou-se a análise e discussão dos resultados, encerrando o trabalho com as conclusões.

\section{Caracterização da comunidade de Glória, zona rural de Estrela/RS e o contato Pt-Hr}

Segundo Raso, Mello e Altenhofen (2011), a vinda dos imigrantes alemães para o Brasil, motivada pelas oportunidades de trabalho e prosperidade econômica, alterou a paisagem linguística. Partindo de diferentes regiões, dirigiram-se a áreas do Rio Grande do Sul, Brasil, no início da imigração, em 1824, incorporando às línguas já faladas as línguas trazidas com a imigração.

A partir de 1855, Estrela, localizada no Vale do Taquari, no Rio Grande do Sul, recebeu os primeiros imigrantes alemães. A Linha Glória, na zona rural de Estrela, é um de seus povoamentos mais antigos e tem a agricultura familiar como atividade econômica predominante. As famílias, pequenos núcleos, têm o sustento por meio do setor primário, a produção de leite, suíno, frango, milho, soja e mandioca. No entanto, muitos informantes, principalmente da geração mais nova, voltam-se para as atividades urbanas, em indústrias e no comércio, mas residem na zona rural e realizam esse movimento diariamente.

Nessas novas comunidades, os imigrantes comunicavam-se na língua de seu país de origem e, aos poucos, foram aprendendo o português. Desse contato linguístico, denominou-se $\mathrm{Pt}-\mathrm{Hr}$ os traços linguísticos das variedades dialetais de origem em contato com o português brasileiro local. Como já citado em Lara (2019, p. 49), por contato de línguas, Crystal (2000, p. 64) entende que se refere a "uma situação em que línguas ou dialetos estão em continuidade geográfica ou proximidade social (e assim influenciam-se mutuamente)". Essa situação ocorre em Glória e é importante mencionar que o Hr é uma língua oral, transmitido de geração a geração, enquanto o português tem a institucionalidade e é a língua majoritária na comunidade. Hoje, segundo o levantamento do 
$\mathrm{IBGE}^{4}$, Estrela tem uma população estimada de 34.399 pessoas e Glória tem uma população muito pequena, em torno de 200 pessoas.

Lara (2019, p. 49) já apresentou a definição de Hr, por Altenhofen (1996), como

uma variedade supra regional do alemão falado no sul do Brasil, que tem por base um contínuo dialetal formado essencialmente pelo francônio-renano e pelo francônio-moselano, originários de áreas situadas na Renânia Central, e que recebem, no novo meio (brasileiro), uma forte influência do português e de outras variedades em contato ${ }^{5}$ (ALTENHOFEN, 1996, p. 27).

Ainda, segundo o autor, o Hr é uma língua de imigração de matriz francônio-renana e francônio-moselana. O Hr falado em Glória compartilha traços fonético-fonológicos, como o desvozeamento variável das plosivas bilabial, alveolar e velar, por exemplo, abacaxi apacaxi, dela tela e Glória Clória.

Assim, o contato de línguas, em Glória, pode ser visto como:

O repertório linguístico de um indivíduo é composto de variedades e variantes que o falante ordena/indexa em um contínuo e das quais se serve conforme uma série de fatores, entre os quais a situação, o interlocutor e o tópico da conversa. Assim, tem-se "variedades (do português) em contato", com marcas próprias. (LARA, 2017, p. 32).

Para averiguar o fenômeno linguístico do desvozeamento das plosivas bilabial, alveolar e velar no Pt-Hr, tomou-se por definição em Lara (2017, p. 37), que "as plosivas são, em termos articulatórios, segundo Cristófaro-Silva (2003), segmentos produzidos com uma obstrução completa à passagem da corrente de ar pela boca", sendo vozeados ou desvozeados. Ainda, conforme Lara (2017, p. 38), "Altenhofen (1996) afirma que no Hunsrückisch ocorre uma dessonorização sistemática da consoante em sílaba tônica e pretônica. Esse padrão de dessonorização é que se transfere para o Pt, sobretudo de falantes em que o Hr é língua dominante".

\section{Revisão de estudos de variação e mudança linguística e atitudes linguísticas}

Na Sociolinguística Variacionista, a fala obedece a um padrão sistemático expresso pelas regras variáveis que abrange os elementos condicionadores tanto linguísticos quanto extralinguísticos. De acordo com Labov (2008 [1972], p. 124), "a gramática de uma comunidade de fala é mais regular e sistemática do que o comportamento de um único indivíduo". É pela a análise de regra variável que se revela o comportamento linguístico e social de uma comunidade de fala, neste estudo, Glória.

\footnotetext{
${ }^{4}$ Conforme informações disponíveis em: https://cidades.ibge.gov.br/brasil/rs/estrela/panorama. Acesso em: 10 mar. 2020.

5 Original: "Hrs." ist der Oberbegriff für eine überregionale Varietät des Deutschen in Rio Grande do Sul/Südbrasilien, die ein Dialektkontinuum darstellt, dessen sprachliche Konstitution auf eine rhein/moselfränkische Basis zurückgeht und eine Vielfalt sprachkontaktbedingter Elemente anderer deutscher Dialekte sowie insbesondere solche des Ptg. einschließt.
} 
Para este estudo de variação linguística, averiguaram-se os fatores linguísticos e extralinguísticos que influenciaram a aplicação de regra variável. Tais fatores condicionantes, vistos como um conjunto de condições possíveis, apontaram e determinaram a mudança linguística em curso na comunidade de fala pesquisada, atuando de forma a restringir ou pressionar o aparecimento de algumas formas que levam à mudança.

Esta pesquisa traz de forma inédita o estudo do desvozeamento das plosivas vozeadas /b d g/, produzidas como [p t k] (bloco ploco, dar tar, galo calo), sob a perspectiva teórica da Sociolinguística Variacionista laboviana combinada ao estudo de atitudes linguísticas. Estudos de Schneider (2007) e de Gewehr-Borella (2014) incluem o desvozeamento das plosivas no contato português-alemão entre seus objetos de investigação, sob diferentes perspectivas teóricas e metodológicas.

O estudo de Schneider (2007) objetivou averiguar a alternância de português-alemão (HR) em estilos de fala mais ou menos monitorados e a não diferenciação entre consoantes surdas e sonoras, sob o enfoque teórico da Sociolinguística Interacional. A autora pesquisou as práticas sociais de professores envolvendo as (des)sonorizações das oclusivas /p, b, t, d, k, g/ e das fricativas /, $3 /$, em três comunidades bilíngues de contato português-alemão do Rio Grande do Sul. Os resultados indicaram que o uso alternado de português-alemão está ligado de forma muito forte às identidades de grupo e de colono. A autora constatou que o uso alternado está determinado pelo grau de domínio de ambas as variedades pelos interlocutores e pelo grau de exigência de um estilo de linguagem mais ou menos monitorado ou (in)formal entre os interlocutores (SCHNEIDER, 2007, p. 149), pois quanto maior o domínio das variedades, com um estilo mais monitorado (mais formal) entre os interlocutores, maior é a possibilidade de vozeamento.

Gewehr-Borella (2014) pesquisou sobre a descrição da variação de sonorização e de dessonorização das oclusivas /p, b, t, d, k, g/ na fala em português de falantes de hunsriqueano sob a perspectiva macroanalítica e pluridimensional. A autora coletou os dados para a análise por meio da leitura em voz alta de um trecho da Bíblia, a parábola do filho pródigo, em uma situação de uso formal. Na leitura da parábola, Gewehr-Borella (2014) verificou o número de aplicações dos processos de sonorização e de dessonorização e os condicionamentos linguísticos que favoreceram as transferências do hunsrückisch para o português. Por fim, a autora indica o fato de que a variável sonorização e dessonorização das oclusivas encontra-se em um processo de mudança linguística em curso. Conforme GewehrBorella (2014, p. 155), "daqui alguns anos, muito provavelmente, as transferências referentes às oclusivas não serão mais observadas na fala de falantes hunsriqueanoportuguês."

Para melhor compreender este processo de pressões linguísticas, optou-se por associar a esta pesquisa os estudos de atitudes linguísticas, a fim de mensurar o comportamento linguístico dos falantes e sua relação com os padrões variáveis locais. Assim, verificou-se que as atitudes linguísticas locais e os julgamentos linguísticos dos informantes 
da pesquisa podem impactar o processo de difusão ou redução das formas variáveis em questão e, até mesmo a vitalidade da língua minoritária, o $\mathrm{Hr}$.

De acordo com Vandermeeren (2005),

A força da relação entre as atitudes linguísticas e suas manifestações é moderada por variáveis situacionais. Consequentemente, uma mesma atitude pode levar a manifestações que parecem incompatíveis umas com as outras por causa do impacto da mudança de variáveis de contexto (VANDERMEEREN, 2005, p. 1321).

A autora argumenta, ainda, que as atitudes linguísticas se manifestam no comportamento linguístico, sob influência de aspectos situacionais, por exemplo, em relato, um informante afirmou que não se sente à vontade para conversar com um amigo quando há outras pessoas desconhecidas no mesmo ambiente.

Segundo Labov (2010), as atitudes linguísticas são caracterizadas pelos atos de identidade de um indivíduo no seu grupo, no uso da língua. Dessa forma, em situações de monolinguismo ou de bilinguismo, a sociolinguística propõe o estudo das atitudes linguísticas para elucidar fenômenos como perda, manutenção ou difusão de variedades linguísticas em função da avaliação de formas ou manifestações linguísticas.

Kaufmann (2011, p. 122) confirma que normas sociais derivam da "fossilização das atitudes da maioria dos membros de um grupo em questão". Por isso, as atitudes linguísticas de um falante podem refletir as normas do grupo a que se relacionam em sua comunidade, atestando significado social. Assim, sob o enfoque teórico sociolinguístico, este estudo mensurou o impacto das atitudes em relação atitudes ao padrão de desvozeamento variável sobre o Pt em contato com o $\mathrm{Hr}$.

\section{Métodos e procedimentos metodológicos}

De acordo com Labov (2008 [1972]), a Sociolinguística Variacionista ou quantitativa utiliza-se do método de análise de regra variável para verificar os fatores favorecedores ou não, tanto linguísticos como extralinguísticos, da aplicação da regra variável em questão, ou seja, do desvozeamento variável das plosivas / $\mathrm{b} \mathrm{d}$ g/ na fala em Pt-Hr.

O estudo de atitudes linguísticas obteve os dados apenas via aplicação de questionário adequado à complexidade e aos informantes, de forma a captar a projeção de valores sociais, comportamentais e linguísticos em Glória.

Procedimentos metodológicos para a análise (quantitativa) de regra variável

A análise estatística foi realizada com o auxílio do pacote de programas computacionais VARBRUL, versão GoldVarb X (SANKOFF; TAGLIAMONTE; SMITH, 2005), para realizar análise estatística de regressão e verificar o efeito dos grupos de fatores controlados sobre a variável dependente (do desvozeamento variável das plosivas) (via peso relativo) nos dados de fala. Para realizar a análise, codificam-se os dados de acordo com a variável 
dependente e as variáveis independentes propostas: contexto fonológico precedente e seguinte, tonicidade da sílaba, número de sílabas, gênero, idade e escolaridade.

Resumidamente, de acordo com Lara (2017, p. 58-60), as hipóteses foram: a) o contexto fonológico precedente vazio tende a condicionar a aplicação da regra, por exemplo,_gosto,_galinha,_ganhar. A ausência de segmento pode exercer influência na realização das plosivas velares; b) no contexto seguinte, a hipótese é de que a vogal central tende a favorecer o desvozeamento, como em: toda, jogador, segunda; c) na tonicidade da sílaba, a consoante-alvo localizada na sílaba tônica é favorecedora da aplicação da regra variável; d) esperou-se que a aplicação da regra variável fosse condicionada por palavras cujo número de sílabas é menor, em monossílabos (da, de, gol) e dissílabos (dele, depois, pegar); e) o gênero feminino condiciona a aplicação da regra variável; f) o grupo etário que compreende 47 anos ou mais anos favorece a aplicação da regra; g) os níveis de escolaridade ensino fundamental e ensino médio condicionam o fenômeno linguístico.

Os dados submetidos à análise de regra variável foram levantados de vinte e quatro entrevistas sociolinguísticas com informantes de Glória. Também, uma ficha social foi preenchida com informações de cada informante e após foi realizada uma entrevista gravada, semiestruturada, conforme o roteiro elaborado por Lara (2013). Os vinte e quatro informantes foram distribuídos em três faixas etárias (de 15 a 30 anos; 31 a 46 anos e de 47 anos ou mais), três níveis de escolaridade (ensino fundamental, ensino médio e ensino superior) e dois gêneros (feminino e masculino).

A comunidade de fala, aqui representada pela comunidade de Glória, compartilha de traços linguísticos que se reconhece como pertencentes ao grupo comunitário, e tal ambiente se difere de outros grupos sociais; ao compartilhar tais traços, representam padrões e normas de uso dessa comunidade, ao realizarem a variação estratificada na fala (LABOV, 2008 [1972]).

Para além dessa concepção, Guy (2000) apresenta três fatores característicos para definir comunidade de fala: (1) características linguísticas que são compactuadas e usadas na comunidade e que não são usadas fora dela; (2) densidade de comunicação dos grupos sociais da comunidade devem ser relativamente alta, internamente e entre os indivíduos dos grupos; e (3) normas compartilhadas em comum do uso da língua, da direção da variação estilística e das avaliações sociais a respeito das variáveis linguísticas. Ao conceber tais definições, a comunidade de Glória é a comunidade de fala dessa pesquisa por

apresentar um falar em Pt que lhe parece típico (características linguísticas compartilhadas), atribuíveis ao contato com o $\mathrm{Hr}$, nela os habitantes se conhecem mutuamente (comunicação interna possivelmente alta), dada sua extensão territorial e população relativamente pequena. (LARA, 2017, p. 30).

\section{Procedimentos metodológicos para a análise de atitude linguística}

A investigação de atitudes linguísticas procedeu-se com base em dados obtidos por meio da aplicação do questionário "As atitudes linguísticas no Português em contato com o 
Hunsrückisch", de Lara (2017). Os mesmos vinte e quatro informantes responderam o instrumento metodológico e os dados receberam o tratamento estatístico do software IBM SPSS (versão 22.0).

O questionário foi organizado da seguinte forma, conforme Lara $(2017$, p. 64$)$ e Lara (2019, p. 51):

\begin{abstract}
a) identifica-se o perfil dos informantes (Bloco I - Informações gerais);
b) medem-se as percepções e as avaliações das formas linguísticas pelos falantes nas interações sociais na comunidade, com amigos, no trabalho e nas diversas relações sociais, também fora da comunidade (Bloco II - Línguas e seu uso: II-1 Línguas; II-2 Hunsrückisch; II-3 Português e II-4 Uso das línguas);

c) medem-se os aspectos atitudinais e comportamentais que revelam a conduta, os posicionamentos e os modos de proceder ou manifestar-se perante a(s) língua(s) falada(s) na comunidade. As avaliações dos informantes refletem uma forma positiva, negativa ou neutra (indeciso) ao falarem o $\mathrm{Pt}$ e/ou o $\mathrm{Hr}$ com as outras pessoas, em diversas situações (Bloco III - Línguas, pessoas, atitudes: III-1 Línguas e pessoas e III-2 Atitudes pessoais);

d) identificam-se as marcas identitárias construídas através das atitudes linguísticas dos falantes e de seus comportamentos, bem como as normas valorativas na fala em Pt em contato com o Hr (III-3 Os alemães são; III-4 A língua portuguesa é; III-5 Os brasileiros são; III-6 O Hunsrückisch é; Bloco IV - Países e Bloco V - Qualidades pessoais mais importantes) (LARA, 2017, p. 64).
\end{abstract}

As perguntas ofereceram opções de respostas organizadas em escala de diferencial semântico, pois abrange extremos que se situam em polos opostos de uma determinada característica. Assim, em algumas questões, o informante precisou marcar uma das 5 possibilidades de respostas, conforme a escala: "concordo plenamente - concordo indeciso - não concordo - não concordo de modo algum". Em outras, os informantes optaram por respostas dispostas em uma escala com graus de intensidade "bastante", "muito" "pouco" e "indeciso".

\title{
Análises e discussão dos resultados
}

\section{Análise de regra variável}

Para verificar os condicionadores que influenciaram a variável dependente, ou seja, o desvozeamento das plosivas, foram analisados 19.317 contextos de palavras com plosivas sonoras (de 24 informantes), e obteve-se 507 ocorrências em que houve desvozeamento, representando $2,6 \%$ do total de dados. O resultado obtido para a baixa aplicação do processo está de acordo com a literatura, conforme Gewehr-Borella (2014). Optou-se por apresentar a ordem de seleção das variáveis independentes pelo programa, a partir da mais

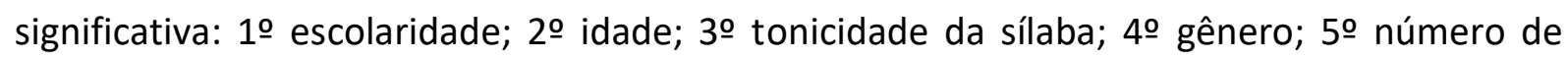
sílabas; 60 contexto precedente; 70 contexto seguinte.

Na sequência, apresenta-se cada variável, de acordo com a ordem selecionada. Primeiramente, para a variável escolaridade, o fator ensino fundamental, menor grau de 
escolaridade, apresentou maior frequência de aplicação do fenômeno linguístico estudado, com peso relativo de $0,91^{6}$, conforme os resultados da Tabela 1 :

Tabela 1 - escolaridade

\begin{tabular}{llll}
\hline Fatores & Aplicação/Total & $\%$ & Peso Relativo \\
\hline Ens. Fundamental & $490 / 8776$ & 5,6 & 0,91 \\
Ens. Superior & $15 / 5843$ & 0,3 & 0,23 \\
Ens. Médio & $2 / 4649$ & 0,0 & 0,05 \\
TOTAL & $507 / 19268$ & 2,6 & \\
\hline \multicolumn{1}{c}{ Input: 0,001} & \multicolumn{2}{c}{ significância: 0,000 } \\
\hline
\end{tabular}

Fonte: Lara (2017, p. 71).

Esse resultado confirmou a hipótese para a variável escolaridade de que os informantes com o menor grau de instrução, ou seja, com ensino fundamental completo ou incompleto favoreceram o desvozeamento das plosivas. Já os informantes com ensino médio e superior desfavorecem a aplicação da regra variável, pois permanecem mais tempo na cidade desenvolvendo atividades como o trabalho. Como afirma Lara (2017):

As práticas escolares implicam monolinguismo em português. Os informantes mais escolarizados, que têm ensino médio e superior, também são aqueles que exercem atividades profissionais na zona urbana, deslocando-se da zona rural para trabalhar na cidade diariamente. Por consequência, têm maior proficiência em Pt, é maior a probabilidade de anularem os efeitos de influência e transferência do Hr (LARA, 2017, p. 71).

Em seguida, para a segunda variável, a Tabela 2 compreende os resultados para o grupo de fatores idade:

Tabela 2 - idade

\begin{tabular}{lccc}
\hline Fatores & Aplicação/Total & \% & Peso Relativo \\
\hline 47 ou mais & $446 / 7319$ & 6,1 & 0,88 \\
$31-46$ anos & $46 / 6366$ & 0,7 & 0,35 \\
$15-30$ anos & $15 / 5583$ & 0,3 & 0,12 \\
TOTAL & $507 / 19268$ & 2,6 & \\
\hline \multicolumn{1}{c}{ Input: 0,001} & & significância: 0,000
\end{tabular}

Fonte: Lara (2017, p. 72).

Os resultados para a variável idade demostraram que os informantes com mais de 47 anos lideram o desvozeamento das plosivas, com peso relativo de 0,88 , confirmando a hipótese. Justificou-se pelo fato de que:

[...] os mais velhos desenvolvem práticas sociais locais, de eles ainda apresentarem bilinguismo ativo nas comunidades de prática, como escola, coral, bolão, ginástica,

\footnotetext{
${ }^{6} \mathrm{O}$ peso relativo dos grupos de fatores recebe o valor de 0 a 1 para o condicionamento da aplicação da regra variável, sendo que um valor acima de 0,5 condiciona a aplicação da regra e abaixo de 0,5 não condiciona. Quando o valor fica em torno de 0,5 é neutro em relação ao fenômeno analisado.
} 
teatro, grupo de 3a idade, apostolado da oração, vôlei, clube de mães e igreja (LARA, 2017, p. 72).

Em relação à variável tonicidade da sílaba, as sílabas pretônica $(0,81)$ e tônica $(0,72)$ foram favorecedoras da aplicação da regra variável enquanto que a sílaba postônica foi desfavorecedora $(0,12)$, conforme apresentado na Tabela 3. A hipótese para a tonicidade da sílaba não se confirmou totalmente, pois a sílaba pretônica também favoreceu o desvozeamento, e não somente a tônica, como se suspeitava para o português.

Tabela 3 - tonicidade da sílaba

\begin{tabular}{llll}
\hline Fatores & Aplicação/Total & \% & Peso Relativo \\
\hline Pretônica (guria) & $185 / 2919$ & 6,3 & 0,81 \\
Tônica (duas) & $308 / 9580$ & 3,2 & 0,72 \\
Postônica (tarde) & $14 / 6769$ & 0,2 & 0,12 \\
TOTAL & $507 / 19268$ & 2,6 & \\
\hline Input: 0,001 & & significância: 0,000 \\
\hline
\end{tabular}

Fonte: Lara (2017, p. 73).

Quanto à variável gênero, confirmou-se a hipótese de que o gênero feminino tende a promover mais do que o masculino a aplicação de regra variável. Na Tabela 4, são expressos os valores:

Tabela 4 - gênero

\begin{tabular}{llll}
\hline Fatores & Aplicação/Total & $\%$ & Peso Relativo \\
\hline Feminino & $437 / 9722$ & 4,5 & 0,70 \\
Masculino & $70 / 9546$ & 0,7 & 0,29 \\
TOTAL & $507 / 19268$ & 2,6 & \\
\hline \multicolumn{2}{c}{ Input: 0,001} & Fignificância: 0,000 \\
\hline \multicolumn{4}{c}{ Fonte: Lara (2017, p. 74). }
\end{tabular}

Observou-se que:

[...] das doze informantes do gênero feminino, 8 permanecem com atividades na zona rural e 4 mulheres trabalham em centros urbanos como professoras, bancária e industriária. A maioria delas permanece mais em casa, em atividades locais. Já dos homens, ( 3 informantes) trabalham nas propriedades rurais, enquanto 9 saem para trabalhar em centros urbanos (LARA, 2017, p. 74-75).

Notou-se que o papel feminino como condicionador do processo está ligado às atividades locais na comunidade, pois as mulheres têm grupos sociais organizados e são líderes comunitárias em que se pratica o Pt com traços do falar hunsriqueano de forma a manifestar uma identidade linguística entre elas.

Para a variável número de sílabas, as palavras trissílabas $(0,61)$ e as polissílabas $(0,57)$ foram favorecedoras do processo. Notou-se que as dissílabas $(0,54)$ ficaram com o peso 
relativo em torno do ponto neutro (próximo de 0,50); e as monossílabas $(0,25)$ desfavoreceram a aplicação da regra variável. A Tabela 5 traz os resultados ${ }^{7}$ :

Tabela 5 - número de sílabas

\begin{tabular}{llll}
\hline Fatores & Aplicação/Total & $\%$ & Peso Relativo \\
\hline Trissílabas (colega) & $156 / 4936$ & 3,2 & 0,61 \\
Polissílabas (complicado) & $73 / 3809$ & 1,9 & 0,57 \\
Dissílabas (dele) & $185 / 6219$ & 3,0 & 0,54 \\
Monossílabas (do) & $93 / 4304$ & 2,2 & 0,25 \\
TOTAL & $507 / 19268$ & 2,6 & \\
\hline \multicolumn{1}{c}{ Input: 0,001} & & significância: 0,000 \\
\hline
\end{tabular}

Fonte: Lara (2017, p. 78).

Percebeu-se que a hipótese para o número de sílabas das palavras analisadas não se confirmou. A proposição afirmava que palavras com maior número de sílabas fossem as desencadeadoras da aplicação da regra variável, pois a tendência foi a de aplicação do desvozeamento na sílaba pretônica que aumentou à medida que aumentaram o número de sílabas da palavra.

A Tabela 6, referente à variável contexto precedente, apontou o fator vazio (peso relativo de 0,64 ) como condicionador da aplicação da regra; o fator alveolares (a amalgamação de tepe, fricativa e a lateral alveolar) resultou no ponto neutro $(0,50)$; as vogais central (peso relativo de 0,46 ), anterior e posterior $(0,35)$ e a consoante nasal (peso relativo de 0,39 ) foram desfavorecedoras do desvozeamento ${ }^{8}$.

Tabela 6 - contexto precedente

\begin{tabular}{llll}
\hline Fatores & Aplicação/Total & $\%$ & Peso Relativo \\
\hline Vazio (gosto) & $364 / 8140$ & 4,5 & 0,64 \\
Alveolares (desde) & $10 / 413$ & 2,4 & 0,50 \\
Vogal central (cada) & $51 / 3149$ & 1,6 & 0,46 \\
Nasal (ajudando) & $17 / 2452$ & 0,7 & 0,39 \\
Vogal anterior & e $65 / 5114$ & 1,3 & 0,35 \\
posterior & & & \\
(amigo, tudo) & $507 / 19268$ & 2,6 & \\
TOTAL & & \multicolumn{2}{c}{ significância: 0,000 } \\
\hline Input: 0,001 & &
\end{tabular}

Fonte: Lara (2017, p. 79).

\footnotetext{
7 Note que as ordens de \% e peso relativo são diferentes e podem indicar interação entre variáveis independentes, mas a ordem das porcentagens não está em ordem decrescente. Essa diferença na ordem dos pesos relativos e das porcentagens pode indicar algum tipo de interação entre Número de sílabas com alguma outra variável independente (que entrou na mesma rodada, com Número de sílabas), tais interações entre variáveis serão verificadas em trabalhos futuros.

${ }^{8}$ As interações entre variáveis serão verificadas em trabalhos futuros.
} 
Segundo Lara (2017, p. 79), "o fator vazio confirmou nossa hipótese, talvez porque a ausência de possibilidade de juntura com segmentos/sílabas antecedentes implique a impossibilidade de assimilar vozeamento". Os fatores alveolares, as consoantes alveolares tepe, lateral e fricativa também foram amalgamadas.

Por último, refutou-se a hipótese em relação à variável contexto seguinte de que a vogal central fosse condicionadora do processo de desvozeamento das plosivas. Os resultados da Tabela 7 evidenciaram que a variável contexto seguinte apresentou como condicionantes da aplicação da regra os fatores alveolares (assim como na variável contexto precedente, as consoantes alveolares tepe, fricativa e lateral alveolar também foram amalgamadas), com peso relativo de 0,65 e a vogal posterior $(0,58)$. A vogal anterior e a central foram desfavorecedoras ${ }^{9}$ :

Tabela 7 - contexto seguinte

\begin{tabular}{|c|c|c|c|}
\hline Fatores & Aplicação/Total & $\%$ & Peso Relativo \\
\hline Alveolares (agradável) & $49 / 798$ & 6,1 & 0,65 \\
\hline $\begin{array}{l}\text { Vogal posterior } \\
\text { (fazendo) }\end{array}$ & $140 / 6216$ & 2,3 & 0,58 \\
\hline Vogal anterior (dia) & $224 / 7238$ & 3,1 & 0,45 \\
\hline Vogal central (daí) & $94 / 5016$ & 1,9 & 0,42 \\
\hline TOTAL & $507 / 19268$ & 2,6 & \\
\hline Input: 0,001 & \multicolumn{3}{|c|}{ significância: 0,000 } \\
\hline
\end{tabular}

Fonte: Lara (2017, p. 79).

Compreendeu-se que a análise de regra variável realizada, neste estudo, indicou variáveis linguísticas e extralinguísticas favorecedoras em todas as variáveis, apesar de o número de ocorrências ser baixo, o que representou apenas 2,6\% dos contextos analisados. Também, direcionou que a mudança linguística em curso, isto é, quando ocorre a não aplicação do desvozeamento, está quase completa na comunidade, pois é promovida pelos mais jovens, que têm menor contato com as práticas sociais locais e apresentam pouca ou nenhuma proficiência em $\mathrm{Hr}$.

Portanto, destacou-se importante esclarecer o comportamento linguístico dos falantes de Pt-Hr em Glória por meio da relação entre a análise de regra variável e o estudo de atitudes linguísticas, pois a constatação, por meio da análise de regra variável, de que o desvozeamento das plosivas é baixo, necessitou do estudo de atitudes linguísticas para identificar as razões da possível mudança linguística em curso e o desaparecimento do contato Pt-Hr.

\footnotetext{
${ }^{9}$ As interações entre variáveis serão verificadas em trabalhos futuros.
} 


\section{Análise do estudo de atitudes linguísticas}

Com o intuito de esclarecer como atitudes linguísticas se relacionam ao padrão de desvozeamento variável, avaliou-se uma projeção de valores com um questionário aplicado aos mesmos informantes que forneceram dados para a análise de regra variável - Bloco I do questionário, apresentado na subseção Procedimentos metodológicos para a análise (qualitativa) de atitude linguística.

Após a coleta e averiguação dos dados com o SPSS, verificou-se também a baixa aplicação do desvozeamento das plosivas, como atestada pela análise de regra variável. Isso demonstrou um "resultado indicador de que não há variação, e sim um traço eventualmente manipulado por questões estilísticas, seja em piadas, por exemplo, ou querendo-se construir algum sentido na interação entre os indivíduos de uma comunidade de prática específica" (LARA, 2017, p. 83).

Ao analisar o questionário de atitudes linguísticas (cf. Bloco l), as mulheres são as que mais falam $\mathrm{Hr}$, o que, por seu turno, poderia ter efeito sobre o desvozeamento em português. As alternativas dadas aos informantes foram: i) mantêm a fala dialetal todos os dias (maior frequência); ii) usam o hunsrückisch frequentemente; e ii) usam o hunsrückisch de vez em quando.

Na Figura $1^{10}$, evidenciou-se o cruzamento entre as variáveis proporção de aplicação e gênero:

Figura 1 - Cruzamento entre proporção de aplicação e gênero

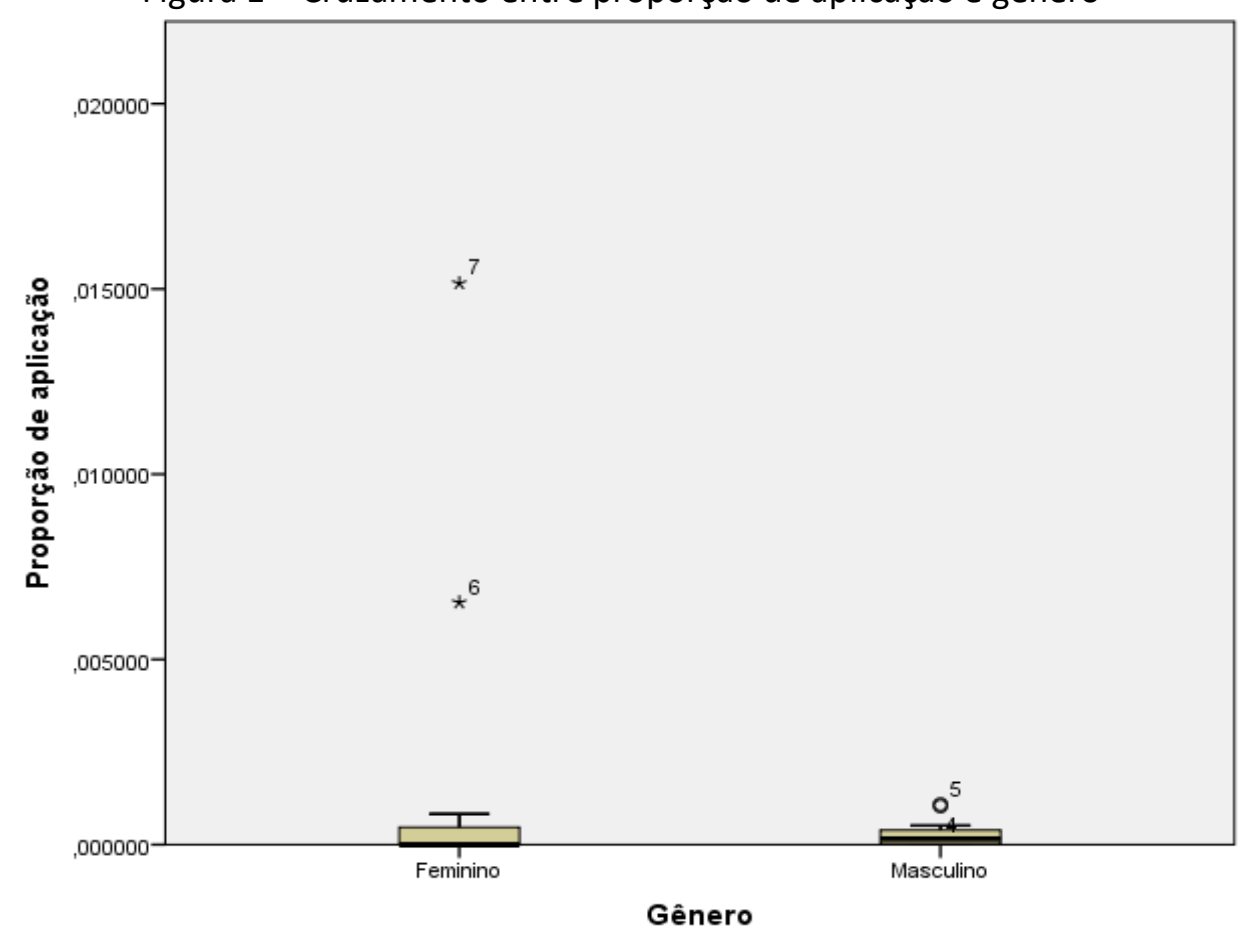

Fonte: Lara (2017, p. 86).

\footnotetext{
${ }^{10}$ A Figura 1 corresponde a Figura 7 em Lara (2017, p. 91).
} 
Outras variáveis se apresentaram significativas. Confirmou-se, no estudo de atitudes, a hipótese para a variável escolaridade, conforme exposto na análise de regra variável. Lara (2017) atestou que

no SPSS, o teste exato de Fisher delimitou 0,59, arredondada para 6\%, a significância da variável escolaridade. Para tanto, os níveis de instrução foram amalgamados, como apresentados na Figura 8 [Figura 2]: (1) ensino fundamental (incompleto e completo); (2) ensino médio (incompleto e completo) e (3) ensino superior (incompleto e completo). Os resultados reforçam o nível de escolaridade ensino fundamental, isto é, fato de ter baixa escolaridade como condicionador do desvozeamento. Como já verificado na análise de regra variável, o resultado obtido no SPSS enfatiza a relação de que quanto maior a escolaridade, a exposição ao português e a idealização de práticas sociais em português, menos ocorre o desvozeamento das plosivas. Ou seja, o nível ensino fundamental é o único que se pode afirmar como significativo (LARA, 2017, p. 87).

A Figura $2^{11}$ mostra o cruzamento entre as variáveis proporção de aplicação e escolaridade:

Figura 2 - Cruzamento entre proporção de aplicação e escolaridade

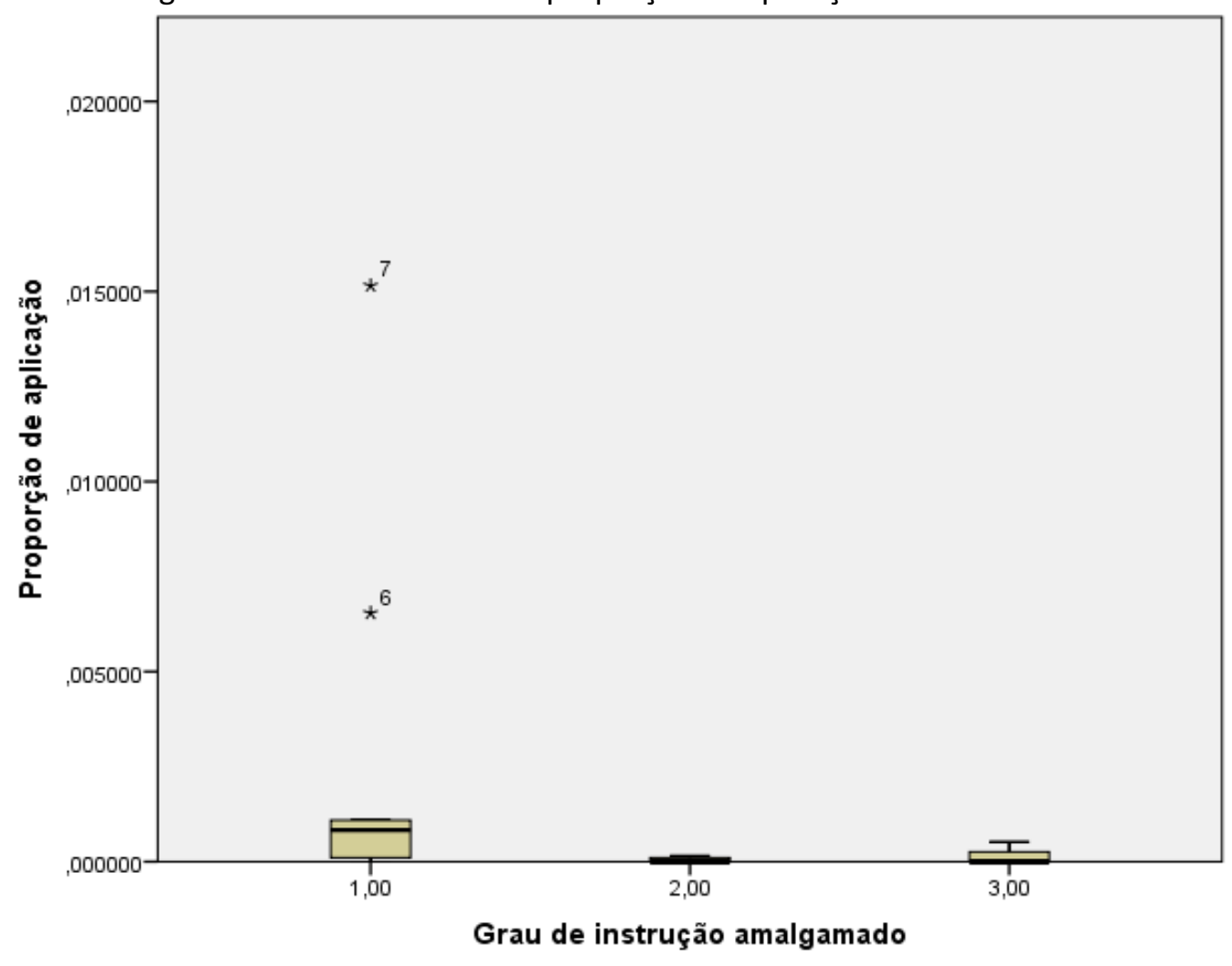

Fonte: Lara (2017, p. 87); Lara (2019, p. 56).

${ }^{11}$ A Figura 2 corresponde a Figura 8 em Lara (2017, p. 87). 
Confirmou-se que o papel da escola é o de promover as práticas culturais conjuntas em português, tornando-se um fator determinante para o progresso do Pt em detrimento do $\mathrm{Hr}$ em comunidades como Glória.

No bloco II do questionário (Línguas e uso - percepção? cf. subseção Procedimentos metodológicos para a análise de atitude linguística), mediram-se a percepção e as avaliações das formas linguísticas pelos falantes nas interações sociais na comunidade, com amigos, no trabalho e nas diversas relações sociais, bem como fora da comunidade. Destacou-se o resultado para a distribuição dos informantes no cruzamento entre a proporção de aplicação do desvozeamento das plosivas e a primeira língua falada por eles. A Tabela $8^{12}$, a seguir, mostrou o cruzamento entre proporção de aplicação e primeira língua:

Tabela 8 - Cruzamento entre proporção de aplicação e primeira língua

\begin{tabular}{|c|c|c|c|c|c|}
\hline & & & \multicolumn{2}{|c|}{ A sua primeira língua é o } & \multirow[b]{2}{*}{ Total } \\
\hline & & & português & alemão $^{13}$ & \\
\hline \multirow[t]{4}{*}{ Aplicação } & nenhuma aplicação & Count & 10 & 0 & 10 \\
\hline & & \% Aplicação & $100,0 \%$ & $0,0 \%$ & $100,0 \%$ \\
\hline & alguma aplicação & Count & 5 & 9 & 14 \\
\hline & & \% Aplicação & $35,7 \%$ & $64,3 \%$ & $100,0 \%$ \\
\hline \multirow{2}{*}{\multicolumn{2}{|c|}{ Total }} & Count & 15 & 9 & 24 \\
\hline & & \% Aplicação & $62,5 \%$ & $37,5 \%$ & $100,0 \%$ \\
\hline
\end{tabular}

Fonte: Lara (2017, p. 91).

Desse modo, o cruzamento entre as variáveis proporção de aplicação e primeira língua destaca que,

do total dos informantes que têm alguma aplicação do processo de desvozeamento, $64,3 \%$ deles têm como primeira língua o alemão. Todos os informantes que adquiriram o alemão antes de falar português contabilizaram alguma aplicação em comparação com os informantes que falaram primeiro português e depois alemão, ou que não falam alemão. Por isso, o grau de bilinguismo se mostra relevante, porque é condicionante. Há relação entre transferência do padrão fonológico do Hr e grau de dominância do Pt (LARA, p. 9192).

Em Glória, notou-se que o uso do Hr tem sido uma prática necessária nas interações familiares e nos grupos sociais. Assim, os falantes de $\mathrm{Hr}$ consideram tal prática como uma marca identitária passada às gerações e mantendo-se nos vínculos atuais, mesmo que de forma restrita. No entanto, estudos de mudança linguística indicam que

[...] a mudança linguística gira em torno de mudanças que pequenos grupos de pouco prestígio protagonizam ao usarem a língua majoritária, do grupo de maior prestígio, pela influência de instituições como a escola e a igreja sobre os pequenos

\footnotetext{
${ }^{12}$ A Tabela 8 corresponde ao Quadro 7 em Lara (2017, p. 91).

13 Usou-se o termo alemão para a generalização de Hunsrückisch pelos informantes.
} 
grupos (FASOLD, 1996, p. 333). Nessa linha, admite-se que as atividades sociais que se realizam em Glória em torno da igreja, como o grupo do coral, teatro, apostolado da oração, bem como a escola são voltadas ao uso do Pt em lugar do Hr. Não somente a religião, também a escolarização e as atividades diárias, como o trabalho e diversão, fornecem fundamentos para que se concretize a mudança em curso (LARA, 2017, p. 121).

Em consonância, Raso, Mello e Altenhofen (2011, p. 28) explanam que "o processo de mudança linguística ocorre tanto sincrônica quanto diacronicamente, e toda língua será sempre uma abstração, formada por variedades e registros distintos em um mesmo momento no eixo temporal". Portanto, o estudo de atitudes linguísticas demonstrou que o processo de implementação da mudança, em Glória, dá-se gradualmente, com o passar das gerações, relacionando as atitudes ao padrão de desvozeamento variável à medida que os informantes se orientam à cultura brasileira e à fala Pt nas práticas linguísticas.

\section{Conclusão}

Neste artigo, abordou-se o estudo do desvozeamento variável das plosivas bilabial, alveolar e velar no contato linguístico $\mathrm{Pt}-\mathrm{Hr}$ e as atitudes linguísticas dos falantes com as línguas em contato. A combinação da análise de regra variável com o estudo de atitudes linguísticas evidenciou que identidades são construídas, representadas pelos grupos sociais formados em Glória, e que normas do Pt são valorizadas na fala em contato com o Hr. Assim também concluiu Schneider (2007), ao mencionar que os resultados obtidos em sua pesquisa indicaram relação forte com a construção de identidade de grupo e da visão de colono quando os informantes usam alternadamente português-alemão.

A análise de regra variável do processo de desvozeamento das plosivas captou o padrão de variação na comunidade, apontando para a proporção total de aplicação da regra de 2,6\%. Concluiu-se que é um índice baixo, um fenômeno residual no Pt de Glória. Quanto às variáveis independentes, os informantes com ensino fundamental completo ou incompleto, os informantes com mais de 47 anos e as mulheres favoreceram a aplicação do fenômeno linguístico em estudo. Também, são favorecedoras as palavras com mais sílabas, trissílabas e polissílabas, o fator vazio no contexto fonológico precedente e o fator alveolar e vogal posterior no contexto fonológico seguinte e as pretônicas, seguidas da sílaba tônica.

O estudo de atitudes linguísticas confirmou que os informantes têm suas percepções e concepções linguísticas, sociais e comportamentais, fundamentadas no repertório linguístico individual e coletivo em Glória. Atestou-se, neste estudo, que o contato Pt-Hr apresenta uma curva descendente, o que pode ser exemplificado com os programas humorísticos que estereotipam a fala em $\mathrm{Hr}$ e a substituição gradual das práticas bilíngues direcionam à fala ao Pt. Dessa forma, o desaparecimento das marcas de contato, como o desvozeamento das plosivas bilabial, alveolar e velar mostrou-se um indicativo do percurso da mudança linguística em andamento e constatada em Glória, corroborando a pesquisa de Gewehr-Borella (2014). 
O caráter investigativo dessa pesquisa, iniciada em 2011 e que culminou em 2017, teve por objetivo retratar a configuração de aspectos fonético-fonológicos do contato $\mathrm{Pt}-\mathrm{Hr}$ referente ao fenômeno linguístico do desvozeamento variável das plosivas e o estudo de atitudes linguísticas para compreender as práticas bilíngues dos informantes de Glória. Constatou-se, por fim, que os informantes mantêm a fala em $\mathrm{Hr}$, bem como atitudes comportamentais e linguísticas em grupos que se identificam e refletem o multilinguismo presente nas esferas familiares ou de maior proximidade, levando de geração em geração, os sentimentos, a língua, os valores construídos localmente, mesmo que a mudança linguística esteja estabelecendo-se. Pois, "É importante, também, notar que a história de uma língua está diretamente associada à história das gerações de seus falantes" (RASO; MELLO; ALTENHOFEN, 2011, p. 28).

\section{Referências}

ALTENHOFEN, C. V. Hunsrückisch in Rio Grande do Sul: Ein Beitrag zur Beschreibung einer deutschbrasilianischen Dialektvarietät im Kontakt mit dem Portugiesischen. Stuttgart: Franz Steiner Verlag, 1996.

ALTENHOFEN, C. V.; MARGOTTI, F. W. O português de contato e o contato com as línguas de imigração no Brasil. In: MELLO, H.; ALTENHOFEN, C. V.; RASO, T. (Orgs.). Os contatos linguísticos no Brasil. Belo Horizonte: Editora UFMG, 2011. p. 289-315.

CRISTÓFARO-SILVA, T. C. Fonética e fonologia do português: roteiro de estudos e guia de exercícios. 7. ed. São Paulo: Contexto, 2003.

CRYSTAL, D. Dicionário de linguística e fonética. Rio de Janeiro: Jorge Zahar Editor, 2000.

FASOLD, R. La sociolingüística de la sociedad. Madrid: Visor Libros, 1996.

GEWEHR-BORELLA, S. "Tu dampém fala assim?": macroanálises pluridimensionais da variação de sonorização e dessonorização das oclusivas do português de falantes bilíngues hunsriqueano-português. 2014. 153f. Tese (Doutorado em Letras) - Programa de PósGraduação em Letras. Porto Alegre. Universidade Federal do Rio Grande do Sul, 2014.

GEWEHR-BORELLA, S.; ALTENHOFEN, C.V. Macroanálise pluridimensional da variação de consoantes oclusivas do português por falantes de hunsriqueano. In: Seminário Internacional de Fonologia, IV, 2012, Porto Alegre. Anais... Porto Alegre: Ed. Instituto de Letras/UFRGS, 2012. p. 1-16.

GUY, G. R. A identidade linguística da comunidade de fala: paralelismo interdialetal nos padrões de variação linguística. Organon, v. 14, n. 28-29, 2000. https://doi.org/10.22456/2238-8915.30194

KAUFMANN, G. Falar Espanhol or Hablar Portugués: Attitudes and Linguistic Behavior on the Brazilian-Uruguayan and Brazilian-Argentinean border. Romanistisches Jahrbuch 60/2009. p. 276-317, 2010.

KAUFMANN, G. Atitudes na sociolinguística. In: MELLO, H.; ALTENHOFEN, C.V.; RASO, T. (Orgs.). Os contatos linguísticos no Brasil. Belo Horizonte: Editora UFMG, 2011. p. 121-137. 
KAUFMANN, G. Attitudes and language behavior at the Brazilian-Uruguayan border. In: NÚÑEZ-MÉNDEZ, Eva (ed.). Biculturalism and Spanish in Contact: Sociolinguistic Case Studies. London: Routledge, 2019. p. 69-91. https://doi.org/10.4324/9781315100357-5

LABOV, W. Padrões sociolinguísticos. Tradução de Marcos Bagno. São Paulo: Parábola, 2008 [1972].

LABOV, W. Principles of linguistic change: cognitive and cultural factors. Malden/Oxford: Wiley-Blackwell, 2010. https://doi.org/10.1002/9781444327496

LARA, C. C. Variação fonológica, redes e práticas sociais numa comunidade bilíngue português-alemão do Brasil meridional. 2013. 105 f. Dissertação (Mestrado em Letras), Universidade Federal do Rio Grande do Sul, Porto Alegre, 2013.

LARA, C. C. Variação fonético-fonológica e atitudes linguísticas: o desvozeamento das plosivas no português brasileiro em contato com o Hunsrückisch no Rio Grande do Sul, Brasil. 2017. 155 f. Tese (Doutorado em Letras) - Programa de Pós-Graduação em Letras, Universidade Federal do Rio Grande do Sul, Porto Alegre, 2017.

LARA, C. C. Atitudes linguísticas do português brasileiro em contato com o hunsrückisch. Polifonia, Cuiabá-MT, v. 26, n. 41, p. 46-60, 2019.

RASO, T.; MELLO, H.; ALTENHOFEN, C. V. Os contatos linguísticos e o Brasil - Dinâmicas préhistóricas, históricas e sociopolíticas. In: MELLO, H.; ALTENHOFEN, C. V.; RASO, T. (org.). Os contatos linguísticos no Brasil. Belo Horizonte: Editora UFMG, 2011. p. 13-56.

SANKOFF, D.; TAGLIAMONTE, S.; SMITH, E. S. GoldVarb $X$ : a variable rule application for Macintosh and Windows, 2005.

SCHNEIDER, M. N. Atitudes e concepções linguísticas e sua relação com as práticas sociais de professores em comunidades bilíngues alemão-português do Rio Grande do Sul. 2007. $261 \mathrm{f}$. Tese (Doutorado em Letras) - Programa de Pós-Graduação em Letras. Universidade Federal do Rio Grande do Sul, Porto Alegre, 2007.

VANDERMEEREN, S. Research on Language Attitudes. In: AMMON, U.; DITTMAR, N.; MATTHEIER, K.J.; TRUDGILL, P. (eds.). Sociolinguistics: An International Handbook of the Science of Language and Society - Volume 2. Berlin/New York: de Gruyter, 2005. p. 13181332.

Recebido em: 20/04/2020.

Aceito em: 14/10/2020. 